\title{
Development of technology for robotic laser welding of thin-walled products from heat- resistant alloys
}

\author{
S.E. Krylova ${ }^{1}$, M.I. Goltyapin ${ }^{1, *}$, S.P. Olesnin ${ }^{2}$ and V.A. Zavyalov ${ }^{2}$ \\ ${ }^{1}$ Orenburg State University, Orenburg, Russian Federation \\ ${ }^{2}$ LLC «Technology», Orenburg, Russian Federation
}

\begin{abstract}
The results of testing the modes of robotic laser welding of spatial welded joints of thin-walled products from heat-resistant steels are considered. Comparative studies of the influence of the parameters of various methods of industrial welding on the metallography of the weld and the technological strength of the welded joint are presented. The resistance of welded joints against the formation of crystallization (hot) cracks is evaluated.
\end{abstract}

Currently, laser technologies in modern production are naturally in great demand, both among large manufacturers and small companies, since they provide a number of advantages that directly affect the consumer characteristics of products: they can improve quality, productivity, reduce costs, and ensure environmental cleanliness production.

With the advent of high-power fiber-optic lasers, new possibilities have arisen for using laser technologies in mechanical engineering. Due to a number of technological advantages, laser welding is effectively applied in the field of manufacturing parts of the aviation industry, allowing the creation of new-generation components, as well as effectively replacing traditional welding methods, providing a number of technological advantages of the process: characteristic welding speeds can reach up to $2000 \mathrm{~m} / \mathrm{h}$; the zone of thermal influence is limited by the area of the laser spot, which provides high technological strength and ductility of welded joints, minimal deformation and residual stresses; a wide range of materials to be welded: from high-alloy high-carbon steel grades to alloys of copper and titanium, ceramics and glass; the possibility of welding dissimilar materials; good controllability and flexibility of the process; beam movement along the surface of a part of any trajectory; the possibility of full automation.

The development of modern robotics in conjunction with laser welding technology has made it possible to minimize the influence of the "human factor" during welding operations, to expand the range of parameters that are modified and monitored during the operation (type and length of the weld, the location of the weld in space, determining the sequence of operations, and the protective filing time gas before and after welding, data for automatic wire release during welding, wire feed and pull speed, geometric seam) [1].

\footnotetext{
* Corresponding author: markgoltyapin@gmail.com
} 
Thus, it became possible to transfer the welding of large-sized thin-walled structures to a new level of quality. Given that promising aircraft should have a speed of $\sim 6000 \mathrm{~km} / \mathrm{h}$, and working conditions at such high-speed modes are associated with stringent requirements for aerodynamics, high operating temperature (from $700{ }^{\circ} \mathrm{C}$ ) and vibration loads, development of robotic laser welding of spatial welded joints thin-walled products from heat-resistant steels are becoming more and more popular and relevant, requiring the use of new structural and technological solutions and materials.

The aim of this work was to develop a technology for robotic laser welding of spatial welded joints of thin-walled structural elements of aircraft components made of heat-resistant steels.

Despite a number of the above advantages of laser welding technologies, the optimization and development of these processes in practice is accompanied by a number of technological difficulties: high-tech and expensive equipment, required by highly qualified personnel, as well as high requirements for materials, assembly quality of the joint (clearance not more than $0.1-0,25 \mathrm{~mm}$ ) and technological equipment for welding spatial joints of complex shape (supply of welding wire to the welding zone with an accuracy of 0.1-0.4 mm; limited weight of equipment; supply of protective gas in the weld zone; stiffness and structural strength to eliminate sway reduction) [2].

Taking into account the above requirements, preferences and limitations to achieve this goal, it was decided to modernize the robotic laser cladding complex existing in the conditions of Technology LLC Orenburg to implement the technology for welding thinwalled spatial elements from heat-resistant alloys. The necessary equipment has been designed for mounting on a manipulator a welding wire feed machine and an optical head of an industrial electric fiber laser IRE-Pole with a power of $2 \mathrm{~kW}$ [3]. The equipment was developed in the CAD / CAM system KOMPAS-3D, Fig. 1

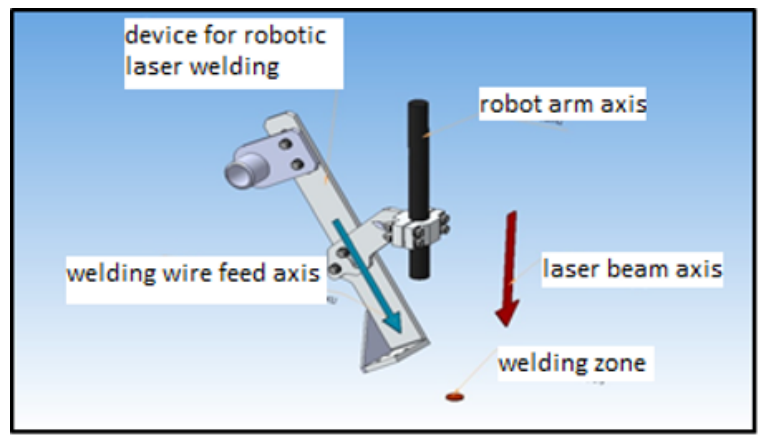

Fig. 1. Layout of the device

All the necessary equipment for performing laser welding operations on a robotic complex was made taking into account the reduction in the mass of the structure from AMg6 and L60 materials. Due to the fact that the KhN50VMKTYUR alloy selected for testing laser welding technology is a complex high-alloyed material, it became necessary to protect the root of the welded joint with argon when it was cooled, for which a bus was made with cooling and the ability to blow protective gas. The main components at the stage of execution and layout are presented in Fig. 2. 


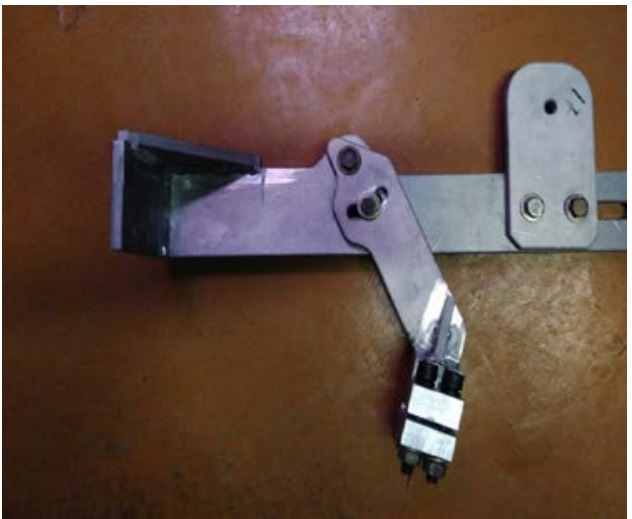

a)

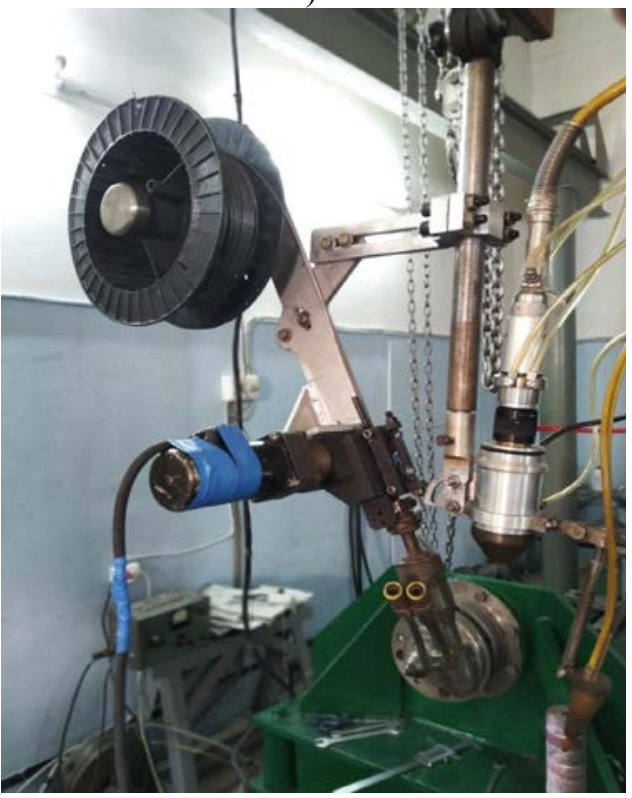

C)

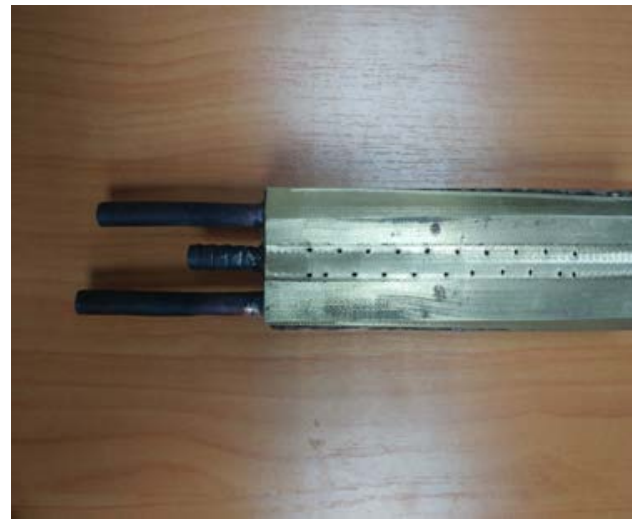

b)

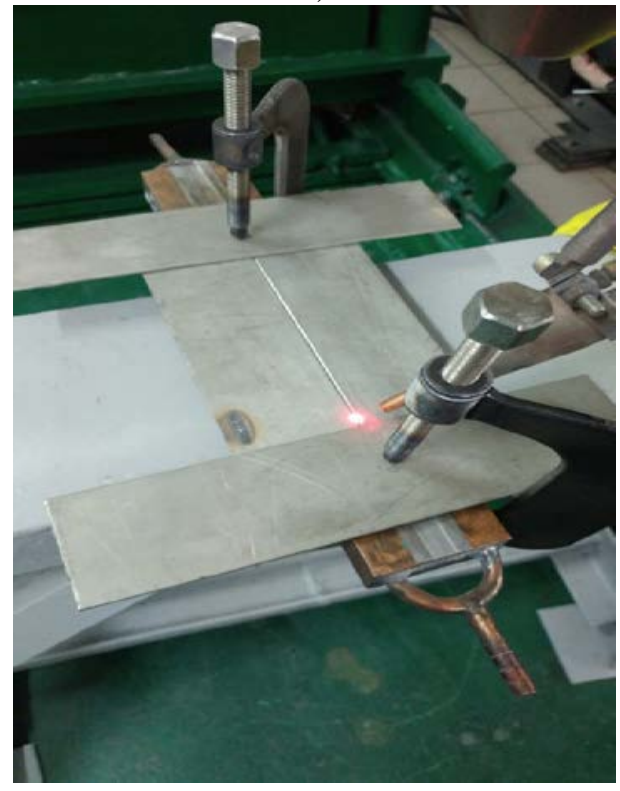

d)

Fig. 2. Developed devices and their layout on the robot manipulator: a - bracket for attaching to the robot manipulator of the filler of the filler material; b - tire with cooling and blowing; c - mounted welding fixture; $\mathrm{d}-2.0 \mathrm{~mm}$ sample mounted on the tire before laser welding

The assembly process was carried out taking into account the need to adjust the focal length of the optical laser head, the twist angle and the departure of the feeding device [4]. To refine the modes of the laser welding process, we varied the main technological parameters: laser radiation power in the range of $0.7-1.8 \mathrm{~kW}$; wire feed speed $1.2-1.8 \mathrm{~m} /$ min. [five]; workpiece movement speed 2.5 - $4 \mathrm{~m} / \mathrm{min}$.; shielding gas supply 5 - $10 \mathrm{l} / \mathrm{min}$. Laser welding modes were tested both with the use of filler material and without it. Optimized parameters of the laser robotic welding mode for the KhN50VMKTYUR alloy are presented in table 1. 
Table 1. Optimized laser welding mode parameters for KhN50VMKTYUR alloy

\begin{tabular}{|c|c|c|c|c|}
\hline $\begin{array}{c}\text { Laser power, } \\
\mathrm{kW}\end{array}$ & $\begin{array}{c}\text { Speed of } \\
\text { movement, } \\
\mathrm{m} / \mathrm{min}\end{array}$ & $\begin{array}{c}\text { Workpiece } \\
\text { rotation speed, } \\
\mathrm{rpm}\end{array}$ & $\begin{array}{c}\text { Wire feed } \\
\text { speed, } \\
\mathrm{m} / \mathrm{min}\end{array}$ & $\begin{array}{c}\text { Shielding gas } \\
\text { supply } \\
\mathrm{l} / \mathrm{min}\end{array}$ \\
\hline 1,2 & 3,5 & 5 & 1,5 & 5 \\
\hline
\end{tabular}

When implementing the welding mode, presented in table 1 , it was possible to synchronize the operation of all components of the laser complex, which ensured both uniform fusion of the filler wire and the main material of the workpiece, and the formation of high-quality butt joints without filler material. Studies have shown that there is a real opportunity to expand the ability to control the properties of a welded joint by increasing the input laser power and welding speed [5]. In particular, with a constant input power of laser beams, changing the welding speed, in the direction of its increase, the parameters of the welded joint decrease. The length and width of the weld pool are reduced, which entails a decrease in the width of the weld and HAZ, structural parameters change, the hardness of the weld metal and HAZ increases, strength increases, and impact strength decreases. In the case of a decrease in the welding speed, an inverse relationship is observed, namely, the width and length of the weld pool increases, which entails an increase in the width of the weld and HAZ, the structure in them enlarges, hardness decreases noticeably, impact strength increases while maintaining strength almost at the level of the base metal.

For an objective assessment of the results obtained, samples were studied after laser welding using the technology described above. Optical and scanning electron microscopy, $\mathrm{X}$-ray microanalysis, ultrasonic testing, and mechanical tests were used as research methods. Metallographic studies were performed using a direct Nikon Eclipse LV $150 \mathrm{~N}$ metallographic microscope, a DuraScan-20 Gs microhardness tester, and a JEOL JCM-6000 Neoscope scanning electron microscope with a wave and energy dispersive analyzer. The geometry of the prototypes for performing structural studies and the macrostructure of the welded joint obtained by laser welding are shown in Figure 3.

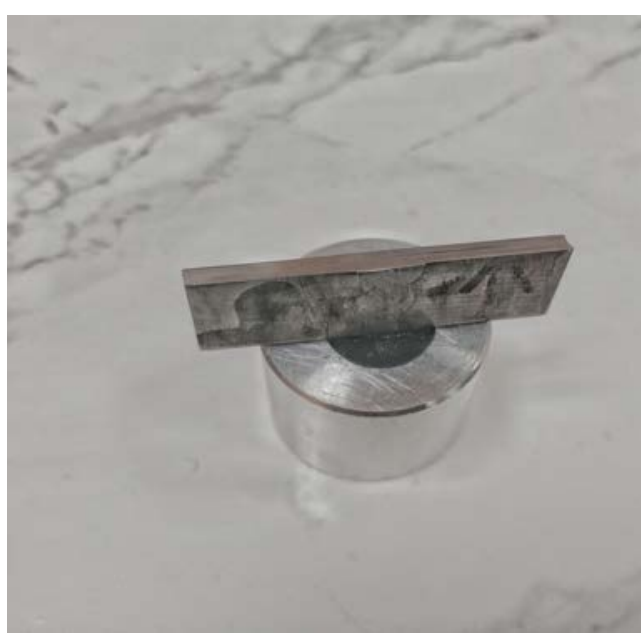

a

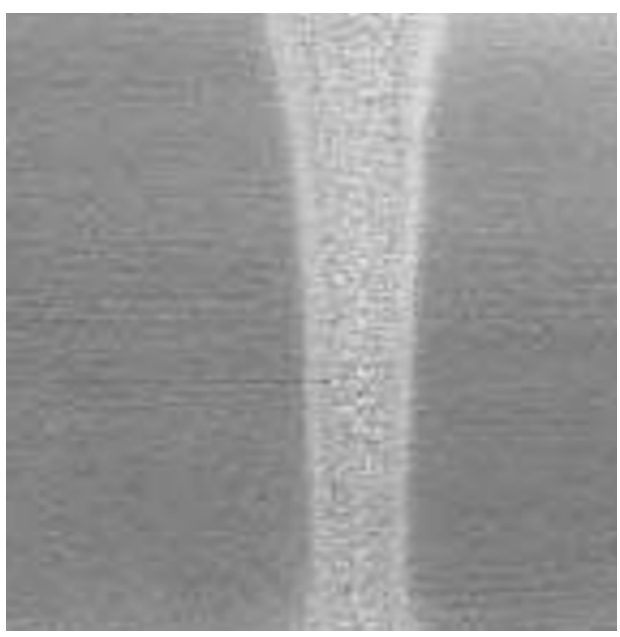

b

Fig. 3. Sample of a welded joint of the material ХН50ВМКТЮР-ИД: a - template for macro- and microstructural studies; b - Form of penetration during laser welding ( $\mathrm{L}=10 \mathrm{~mm}$, Rad. $=1.2 \mathrm{~kW}$, $\mathrm{Vsv}=2 \mathrm{~m} / \mathrm{min})$

A high concentration of focused laser radiation makes it possible to obtain a welded joint with a dagger-shaped penetration [6], (Fig. 3). A comparative analysis of the microstructure 
of the welded joints showed that the cast structure of the weld obtained by laser welding differs from the structure obtained by classical welding methods like TIG and MIG / MAG, not only the characteristic structure of dendritic crystals (Fig. 4), but also significantly shorter heat affected zone.

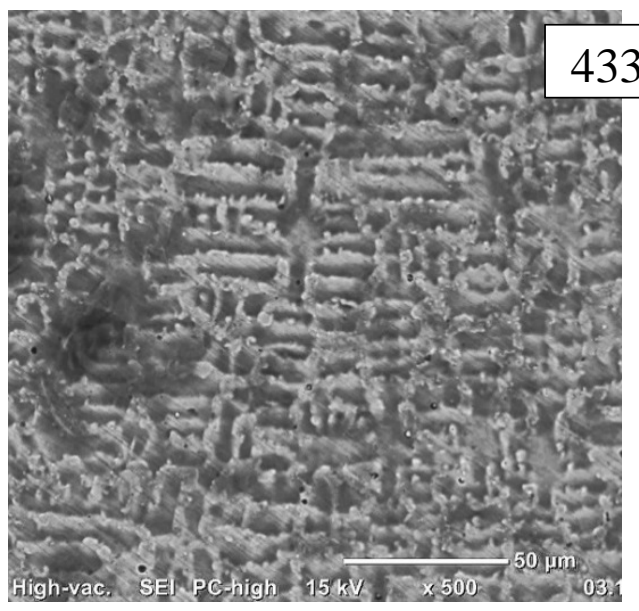

a

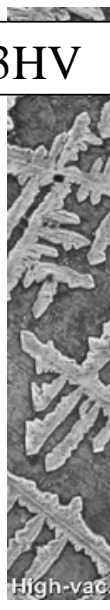

High-var
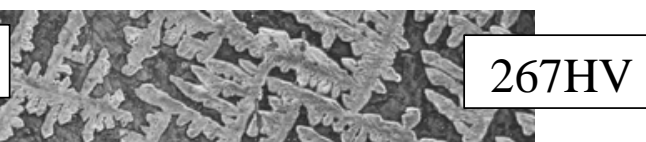
as

Fig. 4. The microstructure of the weld: a - laser robotic welding; b - mechanized argon arc welding

Vickers hardness control showed that laser welding forms a weld, the hardness values of which are $\sim 2$ times higher compared to MAG welding. At the same time, the welded joint has a strength not inferior to the base metal, and ductility that meets all operational requirements for the product.

Considering that the KhN50VMKTYUR-ID alloy is a material with a complex chemical composition (table 2), which has increased heat resistance, heat resistance, and ability to withstand aggressive environments, it is designed to operate parts of turbo and aircraft construction at a temperature of about $950-1050{ }^{\circ} \mathrm{C}$, which has In addition to $50 \%$ nickel, the composition also contains chromium, carbon, phosphorus, sulfur, copper, aluminum, titanium, cerium niobium, and a number of other components, which determines the resistance to cracking in the weld and partially in the heat-affected zone and provides compositions $\mathrm{m}$ Tall weld process with a high strength. For this purpose, additional alloying with molybdenum, tungsten, niobium, chromium, selenium, and cobalt was introduced into the composition of the alloy.

Based on the foregoing, a nickel alloy of the KhN50VMKTYUR-ID grade with carbide hardening is generally considered to be well welded, as it has a slight tendency to the formation of hot cracks and does not form cracks during the heat treatment of welded assemblies and parts [7].

Table 2. Chemical composition of the KhN50VMKTYUR-ID alloy, in\% by weight

\begin{tabular}{|c|c|c|c|c|c|c|c|c|c|c|c|c|c|c|c|c|}
\hline $\mathrm{C}$ & $\mathrm{S}$ & $\mathrm{P}$ & $\mathrm{Mn}$ & $\mathrm{Cr}$ & $\mathrm{Si}$ & $\mathrm{Ni}$ & $\mathrm{Fe}$ & $\mathrm{Cu}$ & $\mathrm{Al}$ & $\mathrm{B}$ & $\mathrm{Ti}$ & $\mathrm{Mo}$ & $\mathrm{Nb}$ & $\mathrm{W}$ & $\mathrm{Ce}$ & $\mathrm{Co}$ \\
\hline$\leq 0$ & $\leq 0$. & $\leq 0$. & $\leq 0$ & 2 & $\leq 0$ & $\mathrm{Ba}$ & $\leq$ & $\leq 0$. & 3. & $\leq 0$. & 1. & 3. & $\leq 1$ & 7 & $\leq 0$. & 8 \\
.1 & 015 & 015 & .4 & 0 & $\begin{array}{c}.5 \\
\mathrm{se}\end{array}$ & 5 & 07 & 2 & 005 & 5 & 5 & .5 & 02 & 8 \\
\hline
\end{tabular}

The cast structure of the welded joint has a uniform dendritic structure, Figure 5. The welded seam and the heat-affected zone retain the austenitic structure over the entire range of temperature cooling from crystallization to negative temperatures. 


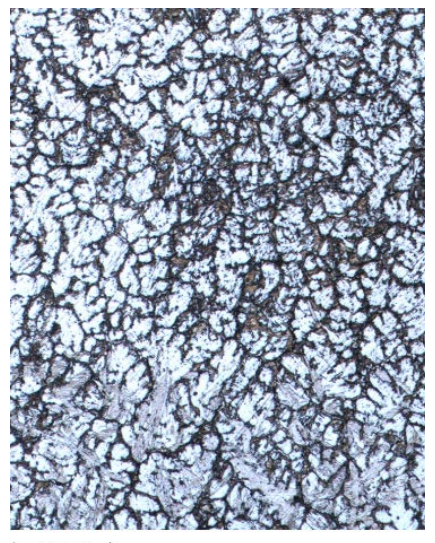

a

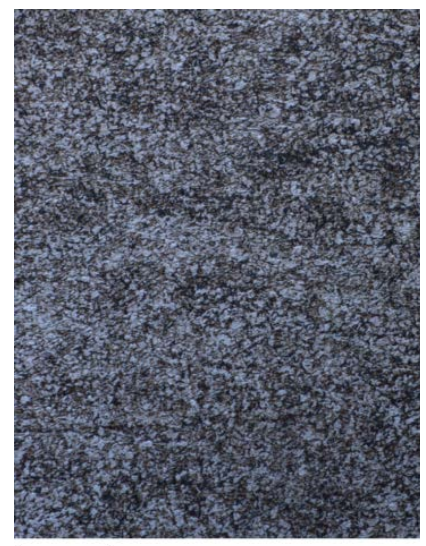

b

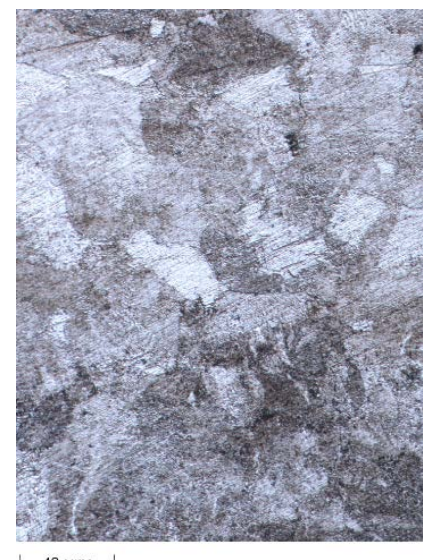

C

Fig. 5. Structure of the welded joint of the KhN50VMKTYUR-ID alloy: a - weld; b - zone of thermal influence; c - the main material

The strength and ductility of the welded joint is close to that of the base metal, table 3 . The structure of the weld metal is characterized by a high content of the $\gamma^{\prime}$-phase, in which, upon cooling in the temperature range $650-850{ }^{\circ} \mathrm{C}$, carbides and $\gamma^{\prime}$-phase are intensively precipitated along the grain boundaries, the content of which should not exceed 6-10\%, since the latter, due to the difference in volumes with the $\gamma$-phase, causes local stresses and leads to a decrease in plasticity along the grain boundaries.

Observations of the weld pool during laser welding show that its geometrical dimensions are very small and the cooling rate in the temperature range of brittleness (SIL) can reach or exceed $2000^{\circ} \mathrm{C} / \mathrm{s}$. In the range of austenite decomposition temperatures, the cooling rate is in the range of $450-600^{\circ} \mathrm{C} / \mathrm{s}$, which helps to minimize the formation of an undesirable $\gamma^{\prime}$-phase in the weld metal.

Table 3. Comparison of the mechanical properties of laser welded joints with indicators of the base metal

\begin{tabular}{|c|c|c|}
\hline Base metal & Actual Values & Required Values \\
\hline Tensile strength, N / mm2 & $510-520$ & $490-588$ \\
\hline Impact strength, J / cm2 & & \\
KCU $^{-60}$ & $147-169$ & 29,4 \\
$\mathrm{KCV}^{-20}$ & $144-151$ & 39,2 \\
\hline Welded joint & Actual Values & Required Values \\
\hline Tensile strength, N / mm2 & $608-628$ & $\geq 588$ \\
\hline Impact strength, J / cm2 & & \\
KCU $^{-20}$ & $147-169$ & \\
$\mathrm{KCV}^{-30}$ & $144-151$ & \\
$\mathrm{KCV}^{-40}$ & $144-151$ & \\
$\mathrm{KCV}^{-60}$ & $144-151$ & \\
\hline
\end{tabular}


Studies of technological strength (table 3) showed that laser welding of steels with high cooling rates of the weld metal in SIL has a favorable effect on the resistance of welded joints against the formation of crystallization (hot) cracks. The higher the welding speed, the lower the likelihood of hot cracking. This is due to the primary structure (Figure 5), which, with an increase in the welding speed, becomes more dispersed and, therefore, more resistant to the occurrence of hot cracks.

In order to confirm conclusions on the results of metallography, the distribution of microhardness in the welded joints obtained by laser welding at a power of $1.2 \mathrm{~kW}$ using a filler wire and contact method was checked, Figure 6. According to the data obtained, it is seen that welding with filler wire provides higher hardness weld metal 361-414 HV than with resistance welding 254-313 HV. From the point of view of the uniform distribution of hardening and minimization of stresses in the weld zone, the optimal method of laser welding with an additive, which allows to increase the volumetric dimensions of the weld pool, which, in turn, leads to a decrease in the cooling rate of the weld metal in the temperature range of austenite decomposition to $120-200{ }^{\circ} \mathrm{C} / \mathrm{s}$ and, as a result, provides a decrease in the hardness of the weld and to a level close to the hardness of the base metal, while the strength and toughness are also close to firs of the base metal (table 3).

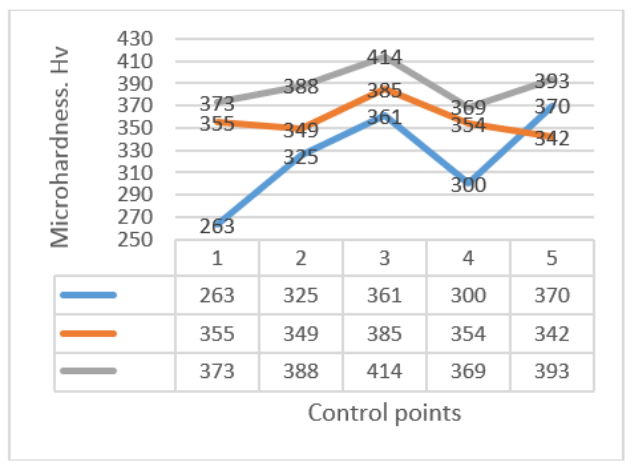

a

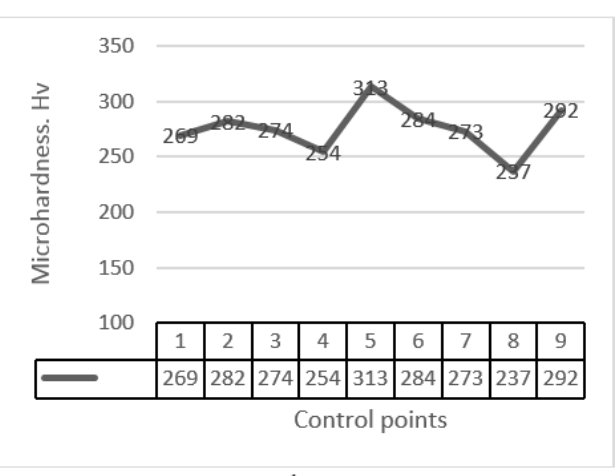

b

Fig. 6. Comparative values of the microhardness distribution of the weld, HAZ and base metal for various methods of laser welding at a power of $1.2 \mathrm{~kW}$ : a - laser welding using filler wire; $\mathrm{b}$ - contact welding

\section{Conclusion}

At this stage of development of technology for robotic laser welding of thin-walled products from heat-resistant alloys, the following main results were obtained:

1. The layout of the experimental installation of welding based on a robotic laser complex was designed. On the basis of full-scale prototyping, the values of the optimal angles and departure of the devices were obtained, the requirements for the equipment necessary for the experiment were determined.

2. Based on the results of the installation layout study and the technological capabilities of the robot manipulator, technological equipment has been developed, optimal requirements for weight and size and strength parameters have been established, on the basis of which technological equipment has been manufactured for testing robotic laser welding technology, welding equipment operating modes are synchronized. 
3. Using the heat-resistant alloy KhN50VMKTUR-ID as an example, laser welding using a filler wire and modes of producing longitudinal butt joints by resistance welding were tested. The results are compared with traditional welding methods.

4. The microstructure and mechanical properties of samples of welded joints obtained in various modes and parameters of laser welding were studied. The results of metallography, monitoring the distribution of microhardness and technological strength showed that laser welding of steels with high cooling rates of the weld metal in the temperature range of brittleness favorably affects the resistance of welded joints against the formation of crystallization (hot) cracks, since the structure of the welded joint becomes more dispersed, and therefore more resistant to cracking.

5. From the point of view of the uniform distribution of hardening and minimization of stresses in the weld zone, the optimal method of laser welding with an additive, which allows to increase the volume dimensions of the weld pool, which, in turn, leads to a decrease in the cooling rate of the weld metal in the temperature range of austenite decomposition to 120 $200 \mathrm{oC} / \mathrm{s}$ and, as a result, provides the formation of indicators of hardness, strength and toughness of the weld and the joint weld joint at the level of the base metal.

\section{References}

1. Terry Vander Werth. Prospects for laser welding in the Russian industry - ensuring the most efficient production process // Kit: ITO. Tool, Technology, Equipment. 2013. No. 3. P. 50-53.

2. Grigoryants, A.G. Technological processes of laser processing: textbook. manual for universities. M .: MSTU im. N.E. Bauman, $2006.665 \mathrm{~s}$.

3. Krylova S.E., Goltyapin M.I., Oplesnin S.P. Influence of gas-powder laser cladding's technological parameters on structural characteristics of corrosion-resistant steels' restored surface layer / IOP Conference Series: Materials Science and Engineering Processing Equipment, Mechanical Engineering Processes and Metals Treatment. 2018. C. 042058.

4. Sotov, A.V., Smelov V.G. Pulse laser cladding of gas turbine engine blades // Bulletin of the Samara State Aerospace University No. 5 (47), part 2. 2013. V. 15, No. 6 (4). S. $973-$ 977.

5. Murzin, S.P., Artyushina V.I. Formation of a welded joint by pulsed laser radiation with an adjustable spatial distribution of power // Bulletin of the Samara Scientific Center of the Russian Academy of Sciences. 2006. T. 8, No. 2. S. 441-444.

6. Dong, W., Kokawa H., Tsukamoto S., Sato Y.S, Ogawa M. Mechanism Governing Nitrogen Absorption by Steel Weld Metal during Laser Welding // Metallurgical and Materials Transactions B. 2004. V. 35, no. 2.

7. Kurochko, R.S. Welding and soldering of heat-resistant materials of the hot tract GTD / VIAM / 1982-198570 / Aviation industry, 1982. No. 8. 